\title{
Atrofia vellositaria duodenal causado por el micofenolato de mofetilo en pacientes con trasplante de órgano sólido: reporte de un caso
}

\author{
Giuston Mendoza-Chuctaya ${ }^{1, a}$, Rubén Nieto-Portocarrero ${ }^{2, b}$
}

\section{RESUMEN}

Los efectos secundarios asociados al empleo de fármacos inmunosupresores son a menudo difícil de establecer, por la presencia de una enfermedad subyacente y al uso simultáneo de otros medicamentos, las reacciones adversas asociadas a la administración de micofenolato de mofetilo consiste principalmente en diarrea, leucopenia, vómitos, además de infección por citomegalovirus. Paciente de sexo femenino de 44 años, presenta un cuadro de 03 meses, presenta náuseas vómitos, diarrea y dolor abdominal tras la toma del micofenolato de mofetilo que se limita tras la no toma del medicamento.

Una buena anamnesis y examen físico así como una biopsia duodenal dan una orientación clara para el diagnóstico.

Palabras clave: trasplante de riñón, diarrea, micofenolato de mofetilo.

\section{Duodenal villous atrophy caused by Mycophenolate Mofetil in patients with solid organ transplantation: case report}

\section{ABSTRACT}

The side effects associated with the use of immunosuppressive drugs are often difficult to establish, by the presence of underlying disease and the concurrent use of other drugs, adverse reactions associated with the administration of mycophenolate mofetil consists mainly of diarrhea, leucopenia, vomiting, besides cytomegalovirus infection.

Female, 44 years old, presents symptomatology of 03 months, vomiting nausea, diarrhea and abdominal pain after taking the mycophenolate mofetil, which is limited after not taking the drug. A good history and physical examination and a duodenal biopsy give a clear guidance for diagnosis.

Key words: kidney transplantation, diarrhea, mycophenolate mofetil.

1. Escuela de Medicina, Universidad Nacional de San Antonio Abad del Cusco, Cusco, Perú.

2. Hospital Adolfo Guevara Velasco, EsSalud Cusco-Perú.

a. Estudiante de Medicina.

b. Médico-Nefrólogo. 


\section{INTRODUCCIÓN}

Las complicaciones gastrointestinales como diarrea persistente después del trasplante de riñón pueden ocurrir hasta en un $20 \%$, el citomegalovirus (CMV) y las infecciones bacterianas son las causas más comunes de la diarrea infecciosa, los dos principales agentes bacterianos responsables de la diarrea crónica son Clostridium difficile y Campylobacter jejuni y las infecciones parasitarias que implican microsporidiun protozoo o Giardia lamblia ${ }^{(1)}$. Este proceso altera la calidad de vida del paciente, causa fatiga y pérdida de peso, y aumenta el número de hospitalizaciones; El Micofenolato de Mofetilo (MMF) es un inmunosupresor que inhibe la proliferación de los linfocitos T y B, actúa inhibiendo a la inosina monofosfato deshidrogenasa indicado para prevenir el rechazo en el trasplante ${ }^{(2,3)}$.

En los pacientes con trasplante de riñón, la incidencia de micofenolato de mofetilo relacionados con efectos secundarios gastrointestinales es poco estudiado y varía de $12 \%$ a $29,6 \%$, desconociéndose su mecanismo, y en consecuencia una mala evolución del injerto renal a los 4 años después del trasplante ${ }^{(4)}$.

\section{CASO CLÍNICO}

Paciente mujer de 44 años de edad, natural de CuscoPerú, tiempo de enfermedad de 3 meses, de inicio insidioso y curso progresivo, paciente presentó náuseas, vómitos, astenia, deshidratación moderada, diarrea crónica, acuosas, abundantes 3 veces por día acompañado de dolor abdominal, una parte importante del relato que conllevó a la resolución del problema fue que los síntomas se agravaban tras la toma de Mifortix (Micofenolato de Mofetilo) que se limita tras la no toma del medicamento, por lo cual acude al hospital del seguro por consultorio externo de nefrología y se decide su hospitalización.

La paciente en el 2008 presentó enfermedad renal crónica por glomerulopatia primaria, ya en el 2009 recibe trasplante renal de donante vivo relacionado, por lo cual fue tratada con tacrolimus, micofenolato de mofetilo y prednisona. Anteriormente tubo 04 hospitalizaciones por sintomatología similar por lo cual en la última hospitalización 2013 se decide hacer una biopsia de duodeno, en la que se encontró duodenitis crónica con aplanamiento de las vellosidades e infiltrado linfocitario moderado (Figura 1).
Figura 1. Atrofia de vellosidades duodenales e infiltrado inflamatorio celular en lámina propia con discreta hiperemia capilar (Grado IIIB de Marsh).

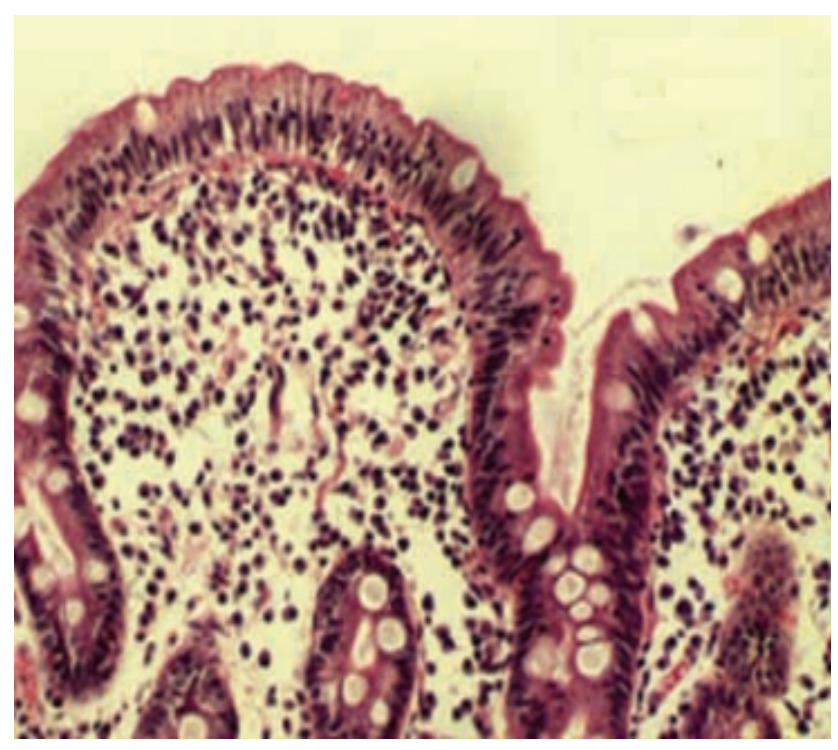

En la fecha de ingreso la paciente presenta una evolución desfavorable con incremento de diarreas acuosas, acompañado de dolor abdominal, malestar general. Se detalla los exámenes complementarios más relevantes en la tabla 1 , y por tales motivos es sometida a diferentes estudios.

Paciente después de los efectos secundarios del uso del micofenolato de mofetilo se decide retirar esta droga de su tratamiento reemplazándola por pulsos de metilprednisolona, ciclosporina y azatriopina.

Tabla 1. Se aprecia los resultados de laboratorio más relevantes para el caso

\section{PRUEBAS DE LABORATORIO \\ $18 / 04 / 13 \quad 28 / 04 / 13 \quad 02 / 05 / 13$}

Hemoglobina Normal $(12,0-15,8 \mathrm{~g} / \mathrm{dL})$

8.9

8.6

8.1

Hematocrito

(36.0-47,4 g/dL )

28.8

26.5

25.3

Creatinina

(53- $106 \mu \mathrm{mol} / \mathrm{L})$

337.1

178.1

Urea $(3,5-5,0 \mathrm{~g} / \mathrm{dL})$

9.7

6.4

Alfa Feto Proteína

5.6

CA 125

17.0

CA 15.3

9.8 


\section{DISCUSIÓN}

El presente caso muestra atrofia vellositaria duodenal a causa del micofenolato de mofetilo, un efecto secundario poco es estudiado y reportado; esta afección fácilmente puede ser camuflado por infecciones bacterianas o virales, o un proceso inmunitario como la enfermedad celiaca que muestra ser la más frecuente ${ }^{(5,6)}$.

Los efectos secundarios asociados al empleo de fármacos inmunosupresores son a menudo difícil de establecer, por presencia de una enfermedad subyacente y al uso simultáneo de otros medicamentos, las reacciones adversas asociadas a la administración de micofenolato de mofetilo consiste principalmente en diarrea, leucopenia, vómitos, además de infección predominantemente por citomegalovirus con la presencia de manifestaciones adversas a nivel gastrointestinal en pacientes tratados con esta droga ${ }^{(7)}$.

El mecanismo de daño en la mucosa intestinal no es claro, postulándose una alteración del microambiente inmunológico determinado por el micofenolato de mofetilo ${ }^{(3)}$.

Las manifestaciones gastrointestinales adversas pueden ser manejadas mediante el uso de protectores de la mucosa gástrica, generalmente asociado a reducción de la dosis o suspensión definitiva del micofenolato de mofetilo, presentándose mejoría clínica luego de suspendido el medicamento con recuperación de la morfología duodenal y colónica en los meses siguientes ${ }^{(6)}$.

\section{REFERENCIAS BIBLIOGRÁFICAS}

1. Gentil MA, Osuna A, Capdevilla L, Cantarell C, Pereira P, Mazuecos A, et al. Daclizumab en combinación con micofenolato mofetil e introducción tardía de tacrolimus a dosis bajas, como opción terapéutica en la pareja donantereceptor añoso en trasplante renal. Soc Española Nefrol Orig. 2008;23(3):28792.

2. Suría S, Checa D. Micofenolato mofetil en el tratamiento de la nefritis lúpica en pacientes con fracaso, intolerancia o recidivas tras tratamiento con esteroides y ciclofosfamida. Rev Nefrol. 2007;27(4):45965.

3. Ticona-Garrón A. Supervivencia del paciente e injerto renal al año de trasplante de donante fallecido; comparación con resultados de donante vivo. Rev Mex ... [Internet]. 2010;70(6):34753. Available from: http://www.medigraphic. com/pdfs/uro/ur-2010/ur106b.pdf

4. Bunnapradist S, Neri L, Wong W, Lentine KL, Burroughs TE, Pinsky BW, et al. Incidence and Risk Factors for Diarrhea Following Kidney Transplantation and Association With Graft Loss and Mortality. Am J Kidney Dis. 2008;51(3):47886.

5. Sáez R. Enfermedad Celiaca. Sist Nac Salud [Internet]. 2010;34(2):28. Available from: http://www.gastronutriped. com/files/publicaciones/publicacion_147.pdf

6. Schorn R, Ho M, Meerbach A, Bossart W, Wu RP, Schreier E, et al. Chronic Norovirus Infection after Kidney Transplantation : Molecular Evidence for Immune-Driven Viral Evolution. Clin Infect Dis. 2010;51(3):30714.

7. Tapia E O, Villaseca H M, Sierralta Z A, Roa S JC. Atrofia vellositaria duodenal inducida por micofenolato mofetil: Caso clínico. Rev Med Chil. 2010;138(5):5904.

Fuentes de financiamiento

Este artículo ha sido financiado por los autores.

Conflictos de interés

Los autores declaran no presentar ningún conflicto de interés.

Correspondencia:

Giuston Mendoza Chuctaya

Dirección: APV Praderas del Inca B-5- San Sebastián, Cusco -

Perú

Teléfono: 984040426

Correo electrónico: giustonmch@gmail.com

Recibido: 03 de marzo de 2016 Aprobado: 15 de abril de 2016 